\title{
Mare crisium: complots y conspiraciones como mecanismo político para el relevo de cúpulas en los regímenes comunistas ${ }^{1}$
}

\author{
Mare crisium: plots and conspiracies as political \\ mechanism to solve the succesion in the Com- \\ munist regimes
}

\author{
Ivan Witker ${ }^{2}$
}

Resumen: Los regímenes comunistas carecían de mecanismos políticos para resolver las disputas en torno al reemplazo del máximo líder dado que no tenían contemplados mecanismos participativos de canalización de las pulsiones internas ni existían espacios para el pensamiento crítico, el disenso, el libre flujo de información y la discusión abierta. El cargo de máxima autoridad parecía estar concebido ad eternum e inmune a la crítica. La vida partidaria interna era gris, estrictamente jerarquizada y con fuerte vigilancia. Por eso, cada relevo estuvo precedido de conspiraciones y deslealtades. El trabajo examina tres casos paradigmáticos de intentos no logrados de relevo relativamente pactado: Roberto Robaina en Cuba, Werner Lamberz en la República Democrática Alemana, y Lin Biao en la República Popular China.

Palabras claves: Regímenes comunistas, RP China, Alemania oriental, Cuba.

Abstract: Communist regimes lacked political mechanisms to solve disputes about how to replace the party and state's leader as they failed to take into consideration participatory mechanisms to channel internal drives. Nor were there spaces for critical thinking, dissent, free flow of information or open discussion. The highest position of authority seemed to be conceived ad eternum and immune to criticism. Inner partisan life was grayish, strictly hierarchical and strongly surveillanced. Therefore, each and every replacement was preceded by both conspiracies and inner disloyalties. The paper examines three paradigmatic cases of unsuccessful attempts of relatively agreed upon succesions: Roberto Robaina in Cuba, Werner Lamberz in the German Democratic Republic and Lin Biao in the People's Republic of China.

Key words: Communist regimes, PR China, East Germany - Cuba

\footnotetext{
${ }^{1}$ Recibido: 30/05/2018. Aceptado: 12/10/2018

${ }^{2}$ Cientista político, periodista por la Universidad de Chile, PhD en Comunicaciones por la Universidad Carlos IV de Praga, República Checa, graduado del CHDS (National Defense University), Washington DC. Actualmente se desempeña como profesor-investigador en la Facultad de Gobierno de la Universidad Central y en la Academia Nacional de Estudios Políticos y Estratégicos de Chile (ANEPE). Áreas de trabajo: actores y procesos de las relaciones internacionales, problemas hemisféricos.
} 


\section{Introducción}

Salvo las transiciones de tipo dinástico ocurridas en Cuba -desde Fidel Castro Ruz hacia su hermano Raúl- y en Corea del Norte con una triple sucesión al interior de la familia Kim (abuelo-hijo-nieto), los regímenes comunistas presentan una regularidad muy específica relacionada con su imposibilidad de generar relevos pactados de un líder a otro. La crisis sucesoria es una particularidad que merece ser abordada con detenimiento.

Para efectos prácticos, es menester asumir que el ejercicio del máximo cargo partidario implicaba de facto la Jefatura de Estado, más allá de la formalidad que rodease su autoridad, ya que la base del mecanismo institucional y fuente de legitimidad, fue siempre el Partido Comunista ${ }^{3}$.

En todos estos regímenes -y por inspiración más leninista que marxista- se consagró constitucionalmente el llamado "rol de vanguardia" o "rol dirigente" del partido, lo que, por un lado, le confería legitimidad, y, por otro, implicaba que la verdadera representación del Estado recaía finalmente en quien ejerciera el cargo de Secretario General, máximo puesto partidario ${ }^{4}$. Las elecciones, sui generis, que se llevaban a cabo en estos regímenes (y perduran en Cuba y Corea del Norte), jamás estuvieron concebidas para renovar los cargos mediante elecciones libres, secretas e informadas, sino para cumplir un papel decorativo. La oposición política no existía tal como lo entiende la democracia liberal lo que generó la denominación disidencia para expresar la voluntad contestataria y marginalizada (Huntington,104)

Ausente la idea schmittiana de "lucha constante" y anulados los "micro-poderes societales" que divisaba Foucault, en estos regímenes de dictadura del proletariado, tan monolíticos como herméticos, se terminaron configurando complejos cuadros de ruptura de lealtades, traiciones, contubernios y conspiraciones a la hora de definirse los relevos. La política se hacía indefectiblemente desde las tinieblas.

La hipótesis central de este trabajo se basa en que la evidencia empírica apunta a relevos en el máximo cargo producidos o por muerte del incumbente o por complots, y que, pese a ello, rara vez se puso en riesgo lo que Huntington denomina institucionaliza-

\footnotetext{
${ }^{3}$ En varios países dominados por la dictadura del proletariado, la posición de Secretario General del respectivo partido se combinaba frecuentemente con algún tipo de formalidad, sea Presidente de la República (como en Checoslovaquia y Rumania) o bien Primer Ministro (Cuba en los años 60 y 70, URSS con Nikita Jrushov), Presidente del Consejo de Estado (RDA, Hungría, Bulgaria, Polonia y Cuba en los años 80 en adelante). En la URSS, desde Brezhnev hasta Gorbachov, no hubo tal combinación y la función de Secretario General del PCUS implicaba automáticamente ser jefe de Estado, aunque dentro de las reformas de Gorbachov se incluyó la creación de la Presidencia de la República en 1990, cargo que él mismo ostentó hasta la disolución de la URSS.

${ }^{4}$ Para Lenin, la fuente última de la moral comunista estaba dada por la partíinost, es decir la fidelidad, la disciplina del partido. Se puede decir que él reemplazó la idea amorfa de la clase social, el proletariado, que visualizaba Marx, por una estructura organizada y consciente, el partido.

${ }^{5}$ Los parlamentos siempre existieron en los regímenes comunistas pero eran aceptados más bien como vestigios capitalistas y no respondían a su naturaleza que, como escribe Huntington, citando a Edmund Burke, "son asambleas deliberativas de una nación, con un interés, el del conjunto, no orientada por propósitos ni prejuicios locales, sino por el bien general, nacido de la razón general del conjunto" (43).
} 
ción política $(22-32)^{6}$. El problema planteado se delimita en un eje básico cual es la imposibilidad estructural de estos regímenes de disponer de un mecanismo regulado, donde estuviese claramente prevista la sucesión del máximo dirigente. Tal ausencia, generó inevitablemente un ambiente abrasivo y lleno de suspicacias cuando determinados ciclos daban muestras de agotamiento.

Así ocurrió en la Unión Soviética (URSS), país emblema y centro geopolítico del comunismo cuando falleció Lenin en 1924. El control partidario fue tomado paulatinamente por Stalin, tras una feroz disputa de tipo intra-generacional que duró cuatro años y desembocó en purgas contra trotskistas, kamenevistas, zinovievistas, bujarinistas y otras facciones.

Fallecido Stalin en 1953, La Unión Soviética ( se sumergió en un ambiente de profunda irascibilidad intra-cupular, por lo que el poder fue asumido por una troika integrada por V. Molotov, G. Malenkov y N. Bulganin, cuyos insolubles conflictos prolongaron las turbulencias, finalizadas con los tres presos y juzgados por sus propios camaradas, al imponerse un complot dirigido por Nikita Khrushov (Brown, p.227) Este, a su vez, fue desplazado en 1964 por una conspiración urdida por N. Podgorny, A. Kosygin y Leonid Brezhnev, cuya armonía se quebró pronto.

Anatoly Dobrynin, quien fuera embajador soviético en Washington durante varias décadas, relata en sus memorias que una de las más grandes disputas soterradas en Moscú a mediados de los 60 fue entre Kosygin y Brezhnev acerca de quién debía representar a la URSS hacia el mundo, especialmente ante Estados Unidos (EEUU). Kosygin partía de la base que era él en tanto Primer Ministro, y Brezhnev que era él en tanto Secretario General del PCUS (Dobrynin,146)

De hecho, en 1967, se realizó una reunión cumbre entre Lyndon Johnson y Kosygin en Glassboro, un pueblo cerca de Nueva York, que sirvió al Premier soviético para acordar una ronda de negociaciones soviético-estadounidenses que pusiera término a la guerra en Vietnam. Semejante protagonismo terminó provocando roces infranqueables con Brezhnev. Se impuso la lógica leninista comentada supra. Venció aquel identificado con el partido, Brezhnev, y no Kosygin, cuya fortaleza radicaba en la burocracia estatal ${ }^{7}$.

Tras la muerte de Brezhnev en 1982, lo reemplazó Yuri Andropov, ex director general de la KGB, como única alternativa para evitar que las luchas fratricidas provocaran un derrumbe prematuro del régimen. Andropov fallece dos años más tarde, siendo reemplazado por el veterano apparatschik ${ }^{8}$, Nikolai Chernienko, a cuyo fallecimiento al año siguiente le sucede una interminable lista de pugnas, congeladas desde la muerte de Brezhnev, tanto entre los sobrevivientes de la vieja guardia comunista y de éstos con las

\footnotetext{
${ }^{6}$ Entiende por institucionalización el proceso por el cual adquieren valor y estabilidad las organizaciones y procedimientos. Indica que el nivel de institucionalización está dado por las variables: Adaptabilidad/Rigidez, Complejidad/Simplicidad, Autonomía/Subordinación y Coherencia/Desunión.

${ }^{7}$ En esta línea, cobra interés la hipótesis de Huntington en orden a que los triunfadores identificaron sus respectivos intereses con los de la organización partidaria y no con la burocracia gubernamental (35).

${ }^{8}$ Término transliterado del ruso que significa "persona del aparato" y cuyo uso sirve para señalar de manera peyorativa a un burócrata o funcionario público, pues pone de relieve el servilismo hacia la ideología dominante y una conducta laboral de condescendencia absoluta con sus superiores jerárquicos. Los apparatchicks solían tener una formación terciaria ad hoc a sus funciones en el Estado capacitándose para ello en escuelas de cuadros con estándares curriculares análogos a los de universidades a los que se llegaba tras rigurosos procesos de selección.
} 
nuevas figuras portadoras del re-cambio generacional, como al interior de ambas facciones.

Como se sabe, triunfó finalmente un pacto compuesto por la facción de emergentes líderes étnicamente rusos con Mijail Gorbachov a la cabeza y de otros igualmente emergentes que lideraban repúblicas no rusas que tenían como figura central al georgiano, Eduard Schevardnadze. La incapacidad de este pacto cupular identificado con la renovación para re-orientar efectivamente al país y para afrontar la grave crisis presupuestaria heredada tras décadas de desgaste en la carrera armamentista, derivó en la disolución de la Unión Soviética.

En estos antecedentes de contexto, se inserta el propósito central de este trabajo, cual es examinar tres casos paradigmáticos de ascenso y desaparición: Roberto Robaina en Cuba, Werner Lamberz en la República Democrática Alemana (RDA), y Lin Biao en la República Popular China. Tres casos reveladores de la imposibilidad de estos regímenes de regular las disputas al interior de cada cúpula gobernante, pese a los deseos o intentos. Los tres son emblemas de la crisis de sucesión.

Los tres, en cierto momento de sus respectivas carreras políticas, fueron designados o percibidos, como grandes herederos e irradiaron la esperanza de llevar a cabo una transición pactada; es decir programada, ordenada y duradera. Los tres llegaron a ser vislumbrados internacionalmente como una especie de jefe de Estado emergente. Sin embargo, ocurrió que el destino se interpuso y el relevo no tuvo lugar.

Lin Biao y Lamberz fallecieron en accidentes aéreos ocurridos en el extranjero, los cuales fueron explicados por el régimen tanto con dificultad como vaguedad. Lin Biao incluso fue declarado abiertamente traidor, pasando posteriormente al olvido. Lamberz también pasó con rapidez de gran estrella del firmamento a un don nadie. Robaina, en tanto, fue por años una especie de alter ego juvenil de Fidel Castro para ser defenestrado sin explicaciones, aunque sin llegar al asesinato. Los tres cayeron en el río Leteo.

La reflexión y las inferencias a partir de los contextos, más la escasa literatura disponible, ayudan a establecer algunas premisas que expliquen los motivos de que cada agotamiento de ciclo condujese de forma inexorable a conspiraciones, traiciones o la espera sibilina de la muerte del incumbente. Estos motivos van desde temas de pureza ideológica, el papel de la historia previa de cada país, las relaciones con la URSS y el lugar que le correspondía a su país en su relación con el espacio geopolítico inmediato regional y mundial, así como el origen étnico o social de los involucrados.

Nuevamente, la idea hegeliana del Zeitgeist permite ordenar el abordaje intelectual de esta interesante faceta de la historia del comunismo mundial.

\section{Roberto Robaina: auge y ocaso}

La solución dinástica cubana tuvo dos capítulos. El primero, marcado por el abandono formal de todos los cargos con que se encontraba arropado Fidel Castro aduciendo incapacidad física y parcialmente mental. El segundo, por el abandono definitivo del poder tras su muerte.

Durante el interregno, Fidel Castro siguió siendo considerado figura central del "proceso revolucionario". Evidencia de aquello es que prácticamente todos los grandes dignatarios que llegaron a Cuba en los años de su postración relativa, tuvieron agendada 
una visita al otrora carismático líder. Sólo tras su fallecimiento, su hermano Raúl pudo asumir a plenitud la jefatura máxima de los diversos órganos del poder y con los años diseñar un complejo esquema colectivo para su propia sucesión, con un Consejo de Estado y de Ministros inter-generacional encabezado por Miguel Díaz-Canel, un funcionario nacido después de la revolución, con su hijo, Alejandro Castro Espín como jefe de un llamado Consejo de Defensa y Seguridad, reservándose el propio Raúl Castro el cargo de Secretario General del Partido Comunista de Cuba.

Por ahora, el intrincado esquema no contempla la figura de Presidente de la República (Brown, 293-313) ${ }^{9}$ Raúl logró consolidarlo tras varios intentos, que, inspirados en la idea de buscar figuras jóvenes, habían fracasado. Estos tuvieron como protagonistas a dos prohijados del propio Fidel, Carlos Lage y Felipe Pérez-Roque. El primero llegó a ser Presidente del Consejo de Ministros y Vicepresidente del Consejo de Estado, mientras que el segundo llegó al puesto de canciller. Abruptamente, ambos fueron defenestrados, acusados de traición y deslealtad ${ }^{10}$.

El reemplazo de Fidel Castro, comenzó a rondar en la cúpula cubana a mediados de los 80, cuando la rebosante salud dejó de acompañar al otrora famoso líder guerrillero. Sin la presencia de los otros grandes de la gesta de 1959, como Ernesto Guevara y Camilo Cienfuegos, y la evidente falta de carisma de su hermano Raúl, llevaron a Fidel Castro a hurgar en las posibilidades de relevo que existían entre las generaciones más jóvenes.

Para ello, indagó en lo que ocurría en la cantera del Partido Comunista cubano (PCC), llamada Unión de Jóvenes Comunistas (UJC) fundada un ya lejano 1962. Allí descollaban las dotes de liderazgo y popularidad de un novel profesor de matemáticas que había ejercido como presidente de la Federación de Estudiantes Universitarios de Cuba, Roberto Robaina.

Amistoso, desenfadado y simpático, conocido por preferir ropa deportiva de color negro y por una agradable informalidad en el trato, el hombre era un líder nato. Todos lo llamaban Robertico. En 1986, fue designado presidente de la UJC.

Cautivado por su personalidad, Fidel Castro lo designó luego diputado y lo promovió a miembro del Politburó del PC, el más joven de la historia de la Revolución Cubana.

\footnotetext{
${ }^{9}$ En la Cuba pre-revolucionaria existía la figura del Presidente de la República; tras huir Fulgencio Batista, asumió provisionalmente Anselmo Alliegro quien duró un día en el cargo y se lo entregó al juez Manuel Urrutia, designado por Fidel Castro antes de entrar con sus tropas a La Habana. Urrutia nombró Primer Ministro a José Miró Cardona. Ambos eran abogados de prestigio en el país y se habían transformado en figuras importantes del movimiento político anti-Batista. A los siete meses en funciones, Urrutia renunció por presiones de Castro, quien designó al Dr. Osvaldo Dorticós como nuevo Presidente, con facultades decorativo. Mientras tanto, el premier J. Miró fue designado embajador en España, renunciando al año siguiente por discrepancias con el curso de la revolución. El cargo de premier lo asumió personalmente Fidel Castro en 1959. Dorticós fue obligado a renunciar en 1976 (suicidándose en 1983) y Fidel Castro asumió como Presidente del recién creado Consejo de Estado, manteniendo el de Primer Ministro. En la actualidad, Raúl Castro mantiene sólo la jefatura del partido.

${ }^{10}$ Lage, médico de profesión, nació en 1951, llegó al poder de manera simultánea con Robaina y cayó en desgracia en 2009. Sin que mediara juicio de por medio o se entregaran antecedentes sobre la acusación de traición, fue enviado a trabajar en cuestiones administrativas en hospitales fuera de La Habana. PérezRoque, nacido en 1965 fue jefe de gabinete de Fidel Castro hasta 1999 cuando reemplazó a Robaina como canciller, siendo destituido junto a Lage en 2009. Según El País de España, ambos fueron sorprendidos por la inteligencia cubana haciendo chistes sobre los hermanos Castro junto a Conrado Hernández, representante de empresas vascas en Cuba.
} 
Robaina, con apenas 36 años, inició así un ascenso no visto previamente en la historia de la Revolución Cubana. Desde entonces se forjó la imagen de príncipe heredero.

En 1993, alcanzó la cúspide al ser designado ministro de Relaciones Exteriores, sin que con antelación haya tenido experiencia en el campo diplomático o en organismos internacionales. Fueron sus años de gloria. Jefes de Estado y Gobierno, ministros y dirigentes comunistas y no comunistas de todo el mundo lo celebraban como emblema de la renovación generacional de la ya vetusta Revolución Cubana. Robaina, en una curiosa simbiosis, representaba la posibilidad de un giro histórico marcado no sólo por su juventud y modales, sino de actitud ante el mundo; una opción que dejaría atrás la mentalidad de búnker, numantina y pro-soviética que caracterizaba a Fidel Castro. Pero si su ascenso fue meteórico, aún más fulminante fue su ocaso. En 1999, sin explicaciones oficiales, Robaina fue alejado del cargo y desapareció por completo de la escena política del país. Se temió lo peor. Las purgas al interior de los países comunistas solían saldarse con la vida y Cuba no era la excepción ${ }^{11}$, pero no. A Robaina se le perdonó tal derecho fundamental. Crípticamente se supo en 2002, o sea tres años después de su caída en desgracia, que estaba siendo expulsado del PCC "por deslealtad a la Revolución Cubana". ¿Qué ocurrió?

Robaina nació en Pinar del Río en 1956 y estudió pedagogía en Matemáticas en la Universidad de La Habana. Su interés por la política y simpatía personal lo catapultaron a funciones relevantes en federaciones estudiantiles y juveniles del régimen. Casi por instinto, Fidel Castro lo seleccionó para trabajar en su entorno en el Consejo de Estado cuando empezó a preparar a figuras de relevo. Desaparecida la URSS, Robaina comenzó a tomar prudente distancia de la imagen verdeoliva de los veteranos revolucionarios y de los opacos apparatchicks. Robertico, con una inusitada capacidad de decisión y actuar autónomos, se convirtió en pocos años en lo que el máximo líder pensaba, su heredero. Representaciones en el extranjero, negociaciones con inversionistas foráneos, lineamientos económicos, entrevistas con medios occidentales y muchos otros asuntos de Estado pasaban por sus manos; todo en nombre de Castro. La designación como canciller en 1993 sólo vino a confirmar lo que se había convertido en la más reciente leyenda nacional. Robertico era el heredero.

De improviso, cuando Robaina preparaba una de sus tantas giras al exterior -a Europa, Venezuela, Panamá y Haití, incluyendo de por medio una cumbre de jefes de Estado iberoamericanos-, el gobierno cubano en un escueto comunicado informó que el "compañero Robaina quedaba liberado del cargo en tanto se le asignen nuevas funciones" y que el nuevo canciller se llamaba Felipe Pérez-Roque. En el texto dado a conocer el 4 de mayo de 1999, se dice de manera muy imprecisa que "en sus más de seis años de trabajo, Robaina realizó los mayores esfuerzos para cumplir las tareas con las cuales en su momento se le responsabilizó". Se añade que "la decisión fue propuesta directamente

\footnotetext{
${ }^{11}$ Uno de los complots menos conocidos en Cuba es el que tuvo como protagonista a un joven comandante de la Revolución, de origen estadounidense, llamado William Morgan. Este olvidado héroe actuó en el frente de Escambray y aparentemente salvó a Fidel Castro de un complot en 1959 y que fue urdido por F. Batista y el dominicano R.L. Trujillo. Junto a Eloy Gutiérrez Menoyo (español) y E. Guevara (argentino) fueron los únicos comandantes extranjeros en la guerrilla de F. Castro. La proclamación del comunismo en 1960 fue rechazada por Morgan (y también por los comandantes H. Matos y E. Gutiérrez Menoyo, entre otros). Fue fusilado y su esposa, cubana, logró salir a Miami en 1980 en el llamado éxodo de Mariel.
} 
por el compañero Fidel Castro, quien presta una especial atención a la política internacional"

Algo se ha especulado acerca de las ideas de Robertico. Algunas entrevistas dan cuenta someramente de ello. Por ejemplo, desde el derrumbe del comunismo en la URSS, Robaina planteaba la necesidad de ir separando las funciones del gobierno y del partido (Der Spiegel 22, p.155), así como propiciar el deshielo en las relaciones de Cuba con EEUU, asunto que señaló como su objetivo prioritario (ídem, p.146)

Tras el comunicado oficial, Robaina pasó a habitar una suerte de terra ignota. Jamás se supo de las "nuevas responsabilidades" que se le iban a asignar. Sin embargo, tres años después, y nuevamente sin mayores explicaciones, un video de Raúl Castro, reproducido por el periódico español El País (02.08.2002), lo acusa de "deslealtad, corrupción y de autoproclamarse candidato de la transición postcastrista" (...) "Raúl Castro reprocha además a Robaina que 'sobrepasó todos límites' en su relación con el ministro español de Exteriores, Abel Matutes"12.

Después de tal trascendido, los diplomáticos cubanos comenzaron a hablar con cierta soltura de prácticas deshonestas y corruptas en que habría caído el excanciller; entre otras, tener contactos no autorizados con empresarios extranjeros y hacer gestiones en su favor, aceptar dinero a cambio de retribuciones no conocidas. En concreto, de recibir de un empresario italiano un juego de muebles de sala y comedor para su casa, y tener una estrecha amistad con el exgobernador mexicano, Mario Villanueva, encausado por pertenecer al cartel de Juárez ${ }^{13}$.

No hay antecedentes que permitan especular en tales acusaciones o con su participación en alguno de los 600 atentados en contra de F. Castro que la versión oficial cubana asegura haber desarticulado. Más bien parece que los hermanos Castro le descubrieron sutiles maniobras destinadas a reemplazarlos en vida. O sea, cabría especular con un complot fallido.

En 2011, se supo que Robaina seguía con vida. Un matutino mexicano, La Jornada de indisimulada simpatía por Cuba- publicó una nota basada en una conversación que habría sostenido su corresponsal en La Habana, Gerardo Arreola en un café (el Chaplin's

\footnotetext{
${ }^{12}$ En ese video, Castro lee la transcripción de una entrevista a solas con Robaina realizada el 5 de abril de 1999. Castro indica que le habría dicho a Robaina que el 11 de noviembre de 1998, Matutes lo llamó por un teléfono celular y que ambos tuvieron este diálogo: "R: ¿Cómo te fue la conversación con Lage?, M: Buena, muy buena conversación, R: yo hablé con Lage. Quedaste estelar. Dejaste muy buena impresión, M: la conversación que voy a tener contigo también va a ser muy buena. Mi candidato siempre has sido tu. En ese momento interviene Raúl Castro: ¿de qué carajo de candidatura estás hablando, Robaina?, qué carajo has estado hablando tú con este hombre? No voy a permitir que gente como tú jodan esta revolución tres meses después de que desaparezcamos los más viejos". En el mismo video, Raúl Castro establece un paralelismo entre Robaina y otro exlíder cubano defenestrado en 1992, Carlos Aldana por presunto complot, y señala "Aldana ambicionaba convertirse en el Gorbachov de Cuba. Yo lo sabía y un día, delante de él, dije que si de Cuba salía un Gorbachov había que colgarlo de una guasima (árbol que se da naturalmente en zonas tropicales caribeñas). Se puso pálido. Cuando lo llamé a mi oficina y lo apreté, se desplomó. Lloró y contó todo". A continuación, Castro recrimina a Robaina no haber asimilado nada de aquella lección. "Castro expulsa del partido a Roberto Robaina, ex ministro de Exteriores" (El País 02.08.2002)

${ }^{13}$ En la nota se indica que Robaina habría aceptado dineros de Villanueva para renovar el edificio de la cancillería cubana en La Habana así como de la embajada cubana en México; incluso habría volado en una avioneta de éste.
} 
café), que Robaina acababa de abrir en el sector del Vedado de la capital cubana. Es el único antecedente de su vida actual.

Allí, indica que ha redescubierto una antigua afición por la pintura. Incluso, se dice en la nota, habría enviado originales para una exposición en un municipio aledaño a la ciudad de Monterrey al norte de México sin mencionar su nombre. Asegura haber expuesto bajo la misma modalidad no presencial en Panamá, Chile y Argentina y que se encuentra a gusto en la pintura abstracta. "Para mí ha significado volver a nacer" habría agregado $^{14}$.

En síntesis, Robaina sintetizó el esfuerzo de Fidel Castro por encontrar un sucesor carismático y rebosante de energía, que quizás le recordase sus propios años juveniles y con quien deseo materializar la idea de un relevo pactado. Sin embargo, la naturaleza del régimen quiso que aquello no se hiciera inviable.

\section{Werner Lamberz: muerte oportuna de un Kronprinz}

En América Latina, este dirigente de la República Democrática Alemana (RDA) fue escasamente conocido, pese a su fluidez en el idioma castellano. En esta región del mundo, Werner Lamberz sólo tuvo ojos para Cuba; allí viajó varias veces y departió con los hermanos Castro y otros líderes de la Revolución Cubana. Pero sus viajes obedecieron a razones no necesariamente ideológicas. Lamberz, un políglota miembro del Politburó del gobernante Partido Socialista Unificado de Alemania (PSUA), tenía por misión entenderse con Estados y no necesariamente con movimientos o partidos políticos. En sus viajes, Lamberz sólo trataba materias militares, económicas o tecnológicas; en suma, temas estratégicos. Visitaba Cuba sólo cuando ese tipo de materias lo requerían.

Visitó 110 países. Por razones propias de la naturaleza de la RDA, su destino preferente por cierto eran países bajo régimen donde imperaba la dictadura del proletariado o aquellos que en la jerga marxista de los años 60 y 70 se denominaba jóvenes estados nacionales, es decir países donde existía la posibilidad de que el comunismo fuese instaurado aunque mantuviesen fuertes características locales, o se encontrasen en proceso de transición hacia una mayor claridad ideológica. Eso lo llevó a extensas giras por Asia, África y países árabes. Fue justamente en uno de éstos últimos donde se encontró sorpresivamente con la muerte. Libia.

Desde entonces, un manto de dudas e intrigas se abalanzó sobre su trayectoria política y su inesperado ocaso. Werner Lamberz se encontraba en la cima de su fulgurante vida política y algunos lo miraban como el gran heredero de Erich Honecker, ya que en pocos años pasó a ser percibido como la cara amable del régimen hacia el exterior, mientras que para la intelectualidad interna, Lamberz era un convencido aperturista.

No hay antecedentes concretos sobre tales percepciones, salvo que el cosmopolita Lamberz era la antítesis de la gris vida de los líderes de la RDA. Debe recordarse que el

\footnotetext{
${ }^{14}$ En diversos blogs se añade que obras suyas se encontrarían también en colecciones privadas en numerosos países, Rusia, EEUU, Suiza, España, Italia, Canadá y otros. Un sitio de internet asociado a Radio Martí, llamado Cubaencuentro.com, informa el 3.4.2009 sobre una exposición de Robaina en la galería Jakim de Buenos Aires, en modalidad no presencial, efectuada a inicios de abril de ese año. Nada de eso ha sido confirmado por medios de comunicación establecidos o páginas web reconocidas.
} 
concepto "cosmopolita sin raíces" fue utilizado masivamente en la época del estalinismo en un sentido peyorativo en contra de intelectuales y funcionarios del partido; entendido básicamente como desviación.

Nacido en la localidad de Mayen in der Eifel en 1929, su infancia estuvo marcada por aspectos sumamente contradictorios, por ser hijo de un dirigente local del Partido Comunista alemán, Peter Lamberz. Este fue apresado por la policía nazi y enviado al frente de combate, desde donde logró huir rumbo a la Unión Soviética. El niño Werner permaneció con la madre en la localidad de Sonthofen, donde asistió a una escuela de elite del régimen nazi, Ilamada Escuela Adolf Hitler. Fue una decisión preventiva de la madre para adaptarse a las circunstancias políticas imperantes. Aún más, Werner se integró a grupos de la juventud hitleriana entre 1939 y 1943.

Tras la muerte de su madre en 1945, coincidiendo con el final de la guerra, se trasladó a la localidad de Lückenwalde -zona de ocupación soviética- donde vivía su padre, ya retornado desde la URSS. Allí hizo estudios de técnico en calefacción y en 1947 ingresó a la juventud comunista, cuya denominación oficial era Juventud Libre Alemana (Freie Deutsche Jugend, FDJ), donde destacó rápidamente por sus dotes organizativas. Al año siguiente fue promovido al Comité Central del PSUA, iniciando una meteórica carrera.

Entre 1950 y 1952, estudia en la Escuela Superior del PSUA en Gut Schmerwitz y al año siguiente es enviado a Moscú al Komsomol, la Escuela Superior de la juventud del Partido Comunista de la Unión Soviética (PCUS). A su regreso es designado encargado como responsable (Referent) para Agitación y Propaganda de la FDJ, siendo enviado en 1955 a Budapest, Hungría como representante de la RDA ante un organismo multilateral de los partidos comunistas del mundo, llamado Federación Mundial de la Juventud Democrática donde permaneció hasta 1959 y descolló por su facilidad para los idiomas.

A su regreso fue el responsable de las relaciones internacionales de la FDJ e ingresó al Buró Político del PSUA y a cargos de dirección en organismos satélites del régimen, como la Sociedad de Amistad con África, el Consejo por la Paz, siendo a la par legislador de la Cámara del Pueblo. En todos, sobresalió por su simpatía personal, trato y liderazgo innato. A partir de 1967, fue parte activa de la emergente facción que lideraba Erich Honecker. Cuatro años más tarde, se convirtió en el principal operador del complot que derrocó a Walter Ulbricht y entronizó a Honecker ${ }^{15}$.

A partir de ese año, tomó la conducción de todos los temas relacionados con las actividades culturales y mediáticas de la RDA mostrando grandes habilidades blandas hacia un sector reacio a colaborar con el régimen. También asumió el manejo de medios de comunicación tanto locales y de otros países comunistas como occidentales, establecien-

\footnotetext{
${ }^{15}$ Stelkens ha escrito la que probablemente sea la reflexión más acabada respecto a la complejidad de la sucesión en los regímenes comunistas y centró su atención en la RDA, específicamente en la transición de Walter Ulbricht a Erich Honecker. En su texto destaca el papel preponderante de Lamberz indicando que fue él quien hizo un viaje secreto a Moscú a fines de abril de 1971 con la finalidad de pedir la venia del Kremlin para proceder a la destitución de Ulbricht. (513). El texto es extraordinariamente rico en detalles respecto a cómo obró el complot en su totalidad. Se trató de un movimiento táctico y por fases ejecutado por la facción de Honecker destinado a ir disminuyendo los espacios de maniobra de Ulbricht, asunto que se iba visualizando incluso en trivialidades, como negarle invitaciones a ciertas ceremonias aduciendo "olvidos administrativos". Primero se le despojó de sus cargos en el partido y meses más tarde en el Consejo de Estado. El golpe final fue dado aprovechando exámenes médicos que debía realizarse Ulbricht dado el rápido deterioro de su salud desde que él detectara las primeras señales del contubernio en su contra $(531,532)$.
} 
do individualmente con algunos periodistas señales de complicidades insólitas para la naturaleza del régimen. "Si tienen dificultades con los burócratas de la cancillería, llámenme a este número" recuerdan algunos corresponsales extranjeros en Berlin oriental (Der Spiegel 22, p.57)

La literatura especializada disponible, adjudica su fulgurante ascenso no sólo a su dominio de doce lenguas extranjeras -de lo que dieron fe múltiples diplomáticos acreditados en Berlin oriental (ibid)-, sino también a una circunstancia fortuita, cual es que el responsable político de los asuntos exteriores de la RDA era Herman Axen, un apparatchick de origen judío, lo que limitaba la receptividad de la acción política germanooriental, especialmente en el Medio Oriente.

En un lapso muy breve, Lamberz se transformó en una especie de canciller de las cosas vitales y "príncipe heredero" (Kronprinz), depositario además de las grandes esperanzas de la intelligentsia de la RDA en orden a conseguir mayores niveles de diálogo internacional y ciertamente ampliar los márgenes de libertad; algo extraordinariamente sensible para los 16 millones de habitantes de un país ubicado en el corazón de Europa. El cosmopolita y políglota Lamberz corporizó la idea de trascendencia internacional por la que tanto bregó la RDA. Era el dirigente capaz de adaptar la perspectiva dominante en el país a las nuevas circunstancias mundiales.

El 4 de marzo de 1978, Lamberz, a la cabeza de una delegación compuesta por cuatro funcionarios de los ministerios de Defensa y Comercio Exterior, más un traductor y un fotógrafo aterrizó en Trípoli, Libia. Una agenda muy relevante le esperaba en ese país, que por aquel entonces enfrentaba tensas relaciones con sus vecinos Egipto y Etiopía. Lamberz llevaba por misión mediar en la crisis libio-etiopí (ambos aliados de la RDA) y firmar millonarios acuerdos para proveer de equipamiento militar a ambos.

Como era usual, el líder Muammar al Gaddafi no lo esperaba en la capital, ya que solía retozar en un campamento en el pleno desierto en la localidad de Wadi Suf al-Jin. Allí lo recibiría el día 6 de marzo. Lamberz abordó el enorme helicóptero presidencial Super Frelon, producido por la francesa Aérospatiale, considerado a la sazón el más potente y seguro de las industrias eurooccidentales de helicópteros. Era el helicóptero favorito de Gaddafi.

Lamberz llegó al campamento con los 4 miembros de su delegación más cinco funcionarios gubernamentales libios y dos pilotos.

Transcurridas tres horas de reuniones de trabajo, Lamberz, inesperadamente para Gaddafi, decide no pernoctar en el campamento y anuncia que tomará el helicóptero de regreso a Trípoli con los mismos acompañantes con que había arribado. A las 21.30 , la nave que lo transporta se eleva sobre el campamento y al ir ganando altura, a aproximadamente 30 metros, un estruendo la transforma en una bola de fuego falleciendo todos los pasajeros en el acto. El accidente generó una situación imprevista. Gaddafi designó de inmediato una comisión investigadora y prohibió el ingreso al país de delegaciones extranjeras, incluyendo una de la propia RDA, que pretendía averiguar in situ las causas. La delegación sólo recibió los restos calcinados.

Con apenas 47 años de edad, Lamberz desapareció de la escena de la RDA. Un ánfora con su nombre fue depositada discretamente en el cementerio central de Friedrichsfelde en el barrio berlinés de Lichtenberg.

Teorías conspirativas proliferaron de inmediato. Los cuerpos calcinados fueron llevados hasta el hospital Charité de Berlin donde se les practicó autopsia sin que fuera 
posible la identificación exacta. Este ambiente de suspicacia respecto a lo que realmente ocurrió en el campamento Wadi Suf al-Jin fue alimentado por el silencio oficial. Sólo mediante un escueto comunicado, la población de la RDA se enteró que el carismático hombre de la nomenklatura era asunto del pasado.

Las conjeturas respecto a las causas de lo ocurrido quedaron en el plano de las especulaciones debido a la imposibilidad de reconstruir la escena de los hechos y ausencia de antecedentes fidedignos. Estas conjeturas van desde un atentado planificado por el servicio de seguridad germanooriental -la Stasi- obedeciendo órdenes de Honecker y contando con la complicidad de su símil libia, la Mukhabarat el-Jamahiriya, hasta un magnicidio de grupos facciosos opuestos a Gaddafi, que equivocaron el blanco (pues se trataba del helicóptero que usaba personalmente el líder libio ${ }^{16}$ ) o bien que simplemente ocurrió un inesperado defecto en el motor. Contra esta última opción habla tanto el estruendo de la explosión como lo poco plausible de que una nave utilizada preferentemente por Gaddafi, líder de un régimen obsesionado con los temas de seguridad, no haya tenido una mantención técnica acorde a aquello.

El destino quiso que Lamberz no se interpusiera en el camino de Erich Honecker, cuyo proyecto era crear lo que bajo su mandato se conocía como sociedad socialista desarrollada. Nunca trascendió si Lamberz procuraba efectivamente imponerse en la conducción del régimen para iniciar un camino aperturista al estilo Gorbachov. No quedaron sus escritos ni tampoco perduraron sus discursos en las diversas instancias partidarias. Sólo quedó el testimonio de quienes lo conocieron. Existe coincidencia en que era un dirigente popular, de trato muy afable y que llegó a ser percibido como el Kronprinz de la RDA. Tampoco se sabe cómo visualizaba el futuro de Berlin oriental y su artificialidad en el contexto europeo. Las versiones periodísticas de la época hablan que sí se estaba transformando en un referente importante de los círculos artísticos e intelectuales que aspiraban a mayores márgenes de libertad. Algo que obviamente Honecker y su entorno rechazaban.

\section{Lin Biao: la traición del "íntimo camarada de armas"}

La era Mao Zedong parte el 1 de octubre de 1948, al ser proclamada la República Popular de China (RPCh) con la derrota de Chiang Kai-shek, quien huye a la isla de Formosa donde instala la República de China, hoy conocida preferentemente como Taiwán. Poco después, el maoísmo desencadena dos grandes procesos políticos, el Gran Salto Adelante (1958-1961) y la Gran Revolución Cultural Proletaria (1966-1976) Un papel central en este último desempeñó el mariscal Lin Biao.

Nació en la localidad de Huanggang, provincia de Hubei en 1907, en el seno de una acaudalada familia de comerciantes que lo envió tempranamente a Shanghai para que continuase su formación secundaria. Allí tomó contacto con grupos cercanos a la Juven-

\footnotetext{
${ }^{16}$ Esta hipótesis cobra fuerza al día de hoy cuando se examina el mapa de los numerosos frentes que tiene el conflicto interno libio y se tiene en cuenta su virulencia inter-sectaria. La etnia gaddafa, a la que pertenecía el líder, es una de las más pequeñas y violentas lo que explica la extrema mano dura con que éste gobernaba su país. El proyecto Joshua que estudia las etnias y tribus del mundo, estima que las etnias que pueblan el territorio libio sobrepasa las 140.
} 
tud Comunista siendo el más destacado el llamado Movimiento 13 de Mayo. También muy joven, se interesó por cuestiones militares y postuló en 1925 a la recién creada Academia Militar de Whampoa en la ciudad de Guanzzhou, donde fue alumno de quien sería posteriormente Primer Ministro y una de las figuras más relevantes de la RPCh durante los 60 y 70, Chou En-lai. También de un general soviético llamado Vasily Blücher muy conectado con círculos militares chinos de la época. Las extraordinarias dotes de Lin Biao le permitieron un rápido ascenso en su carrera militar llegando a ser el tercer protagonista de la gran gesta de la revolución china conocido como la Larga Marcha. Lin, al igual que Robaina y Lamberz, es un personaje que integra una curiosa simbiosis de innumerables talentos. En su caso, el político y milita. El periodista estadounidense que acompañó la Larga Marcha, y luego se trasformara el gran biógrafo de Mao Zedong, señala que Lin Biao era algo retraído y se expresaba muy bien por escrito, siendo considerados referentes sus textos publicados en revistas militares chinas y consigna que años más tarde llegó a encabezar la emblemática Academia Militar de Yana'an (Snow, p.30)

Sin embargo, en 1938, en pleno desarrollo de la Segunda Guerra Mundial, contrajo tuberculosis y sufrió graves heridas producto de un malentendido con desertores japoneses y fue enviado a Moscú para tratamiento médico y servir simultáneamente como representante del Partido Comunista Chino ante la Internacional Comunista. Eso años, estableció vínculos directos con representantes de muchos otros partidos comunistas del mundo y con los principales líderes soviéticos, incluido el propio Stalin. Permaneció allí hasta 1942.

A su regreso pasó a ser comandante en jefe del ejército en Manchuria donde tuvo 280 mil hombres en armas. Las batallas ganadas por él fueron decisivas para derrotar a Chiang Kai-shek. Sin embargo, su debilitada salud le impidió asumir cargos de mayor relevancia y permaneció por años como viceministro de Defensa sin tomar parte en el dramático proceso conocido como Gran Salto Adelante.

Tras signos de recuperación de su salud, acompañó a Chou En-lai a Moscú para negociar el ingreso de la URSS a la guerra de Corea. Luego, su estrecha relación con Mao, lo llevó a aceptar el cargo de Comandante en Jefe de las FFAA y asumir como ministro de Defensa, donde procedió a llevar a cabo una profunda reforma, creando la carrera militar en sus filas y reorganizando los regimientos con una lógica territorial, que resultó decisiva para ganar posteriormente la guerra con la India en 1962.

Concluida la reforma y la guerra, y manteniendo aquella posición, Lin avanzó en roles protagónicos en la difusión del pensamiento de Mao Zedong por todo el mundo. Su texto Viva la victoria de la guerra popular fue el anuncio que Mao tenía aspiraciones universales con una interpretación propia del marxismo y que lo estaba inaugurando de la mano de quien sería su sucesor.

Allí, Lin establece un paralelo en las guerras ocurridas que llevaron al poder al PC en China con los desafíos vigentes en el Tercer Mundo. Así entonces, como se cercaron las grandes ciudades chinas, la perspectiva de Lin era que Asia, África, América Latina y demás áreas rurales cercasen al mundo desarrollado. Por primera vez se presentó la dicotomía campo/ciudad como insalvable bajo una lógica capitalista y, por vez primera también, se hacía una lectura marxista no eurocéntrica. Muchos grupos guerrilleros en todo el orbe asimilaron con entusiasmo esta novedosa perspectiva de enfrentamiento global. 
Alentado con la popularidad de sus escritos en universidades y ambientes juveniles de todo el mundo, Lin reforzó su producción al sintetizar las más llamativos adagios y dichos de Mao, hasta entonces conocidos sólo por su círculo más cercano, en un libro de pequeñas dimensiones llamado El Libro Rojo y que fue de divulgación masiva tanto en China como en el mundo entero gracias a sus numerosas traducciones. Los textos de Lin dieron rienda suelta al sangriento y tumultuoso proceso conocido como Gran Revolución Cultural Proletaria. En 1966, se cobró la primera víctima de este proceso, Liu Shao Shi, quien ejercía nominalmente como Presidente de la República, una formalidad innecesaria a juicio de Lin, quien ya en esos años era figura protagónica de la situación china.

A partir de 1966, la prensa china lo destaca permanentemente como "íntimo camarada de armas de Mao" (Brown, p.325-326) Crea una milicia propia, adjunta al ejército, llamada Guardias Rojos y sus adherentes son mayoría en el Politburó del PCCh. En abril de 1969, el partido y gobierno lo declaran oficialmente sucesor del gran timonel, Mao Zedong.

Luego sobrevino un período de distanciamiento ideológico con la URSS, cuyo régimen Lin calificó de "socialimperialismo". Puede decirse que de la ideología se pasó a la geopolítica en brevísimo tiempo y, encabezado por Lin, Beijing se enfrascó en un choque militar con Moscú en torno a la isla Shenbao en 1969.

En la conferencia de Lushan del PCCh, en septiembre de 1970, Lin le solicitó intempestivamente a Mao que accediera al cargo de Presidente de la República, el cual había sido abolido por su decisión en 1966 cuando purgó a Liu Shao Shi. Mao, suspicaz, se negó. Fue la primera señal de que a Mao le preocupaba el enorme poder adquirido por Lin.

Luego, la posibilidad de abrir un diálogo con EEUU, tras los esfuerzos de Henry Kissinger, termina por enfrentar a Lin con Zhou, su antiguo profesor y respetado camarada. Zhou siempre fue proclive a aceptar las iniciativas estadounidenses. Lin, por su lado, no deseaba avanzar en una línea unilateral con Washington, sino abrirse simultáneamente también con Moscú y jugar de forma paralela un abstruso triángulo geopolítico a tres bandas, pero equidistante que Zhou y Mao estimaban inviable.

La efervescencia llegó a un punto máximo a inicios de 1971. Mao decidió remover a Lin; éste se resiste y abandona Beijing en agosto de ese año sin destino conocido. Semanas más tarde, Mao también. Zhou permanece en Beijing.

El 13 de septiembre, un avión Hawker Siddeley Trident de la Fuerza Aérea china levanta vuelo en horas de la tarde en la localidad de Quinhuangdao, provincia de Hebei y se dirige rumbo al norte. Sin embargo, a las 3 AM se estrella en la frontera chinomongola y fallecen sus ocho ocupantes; aparentemente Lin y su familia más cercana. Las versiones sobre lo ocurrido difieren. La documentación oficial china sobre el incidente fue destruida.

La hipótesis prevaleciente apunta a que un complot (llamado en código "Proyecto 571") planificado por Lin contra Mao y Zhou, para el 8 de septiembre, fracasó por falta de apoyo y decidió huir en un avión que fue derribado por baterías antiaéreas chinas. Otra apunta a un contubernio de seguidores de Lin, que intentan asesinar a Mao para negociar con Taiwán la reunificación del país, lo que produjo un quiebre del Politburó, ya que vino a profundizar discrepancias anteriores. Este intento de asesinato habría motivado a ambos a abandonar la capital, tras lo cual Lin habría decidido irse a la URSS. Una tercera hipótesis apunta a que Lin fue capturado en Beijing junto a su familia y asesinado de 
inmediato. Su hijo, Lin Liguo, un piloto de la Fuerza Aérea, iba con su familia a bordo del avión estrellado tratando de huir de la situación.

Las tres hipótesis adquieren sustento si se tiene ante sí una de las grandes premisas de Mao, en orden a que el poder nace del fusil y no de votos. Los complots fallidos se pagan con la vida. La versión soviética en tanto indica que probablemente el avión se estrelló al ir volando demasiado bajo para evitar los radares chinos.

Tras el incidente, Beijing rara vez volvió a mencionar a Lin, aunque siempre lo hizo de manera cautelosamente negativa. Ello, hasta la muerte de Mao en 1976, cuando emerge públicamente la acusación de haber traicionado al gran líder.

La desaparición de Lin de la escena política china fue lenta y casi imperceptible. En los regímenes comunistas, las apariciones públicas de sus líderes eran escasas y reservadas por lo general a materias protocolares, políticamente significativas y por tanto infrecuentes. El propio Kissinger señala que el gobierno estadounidense no notó que Lin había desaparecido del intercambio de notas que él tuvo con Zhou En-lai mientras preparaba su visita a Beijing. Sólo tiempo después se percató de una ligera variación en los mensajes. Mientras en los primeros, Zhou le decía a Kissinger, que tal punto de la agenda en preparación había sido aprobada por "diversos jefes", el mensaje del 2 de junio señalaba sutil y tangencialmente que el Presidente Mao había aceptado otros temas de la agenda que se negociaba (Kissinger, p.247) Kissinger concluye que en esa fecha ya la suerte de Lin estaba echada y que no habría sido consultado sobre el devenir del acercamiento EEUU/RPCh. Kissinger añade que durante sus conversaciones con Zhou también surgió el nombre de Lin. De nuevo, de manera sutil y tangencial, Zhou le subrayó la necesidad de hablar francamente y sin miedo a micrófonos "esos aparatos no sirven de mucho, nosotros también tenemos nuestros servicios secretos y no funcionan muy bien (Zhou ríe); no supieron lo de Lin y tampoco que Ud. quería venir a China" (Kissinger, p.295)

Lin ha quedado como el gran villano de la historia contemporánea china, posible autor de una conspiración gigantesca, pero cuyos ribetes y contenidos nunca han sido dados a conocer. Aspectos concretos no existen, salvo acusaciones difusas, como la señalada tras la comisión investigadora de los excesos ocurridos durante la Gran Revolución Cultural Proletaria, en que Lin apareció como el gran culpable de los crímenes. Pese a ello, en los últimos años se le ha comenzado a mencionar discretamente como uno de los grandes mariscales que fundaron la RPCh lo que probablemente indique una señal de que el camino a los historiadores se podría abrir en un futuro no lejano para que investiguen las diversas facetas de su vida donde la presunta traición al gran líder es central.

\section{El corazón de las tinieblas: la interminable sucesión de contu- bernios en Europa central y oriental}

Parafraseando a Joseph Conrad, se puede calificar de abrasivo cada final de ciclo en los regímenes comunistas instaurados en Europa central y oriental. En cada caso se divisa un conjunto complejo de rivalidades políticas heredadas junto al engendramiento de otros, nuevos, donde las motivaciones que surgen son aquellas relacionadas con la pureza ideológica, las tendencias nacionalistas, las diversas lecturas de lealtades para con la URSS, cuestiones geopolíticas o bien las actividades de grupos facciosos que sólo preten- 
den mayores cuotas de poder. Los relevos por muerte o mediante tenebrosas conspiraciones fueron las constantes.

En el caso húngaro, el régimen comunista fue instaurado en 1948, de la mano de Mátyás Rákosi, quien se adjudicaba la curiosa cualidad de ser "el mejor discípulo de Stalin" siendo desplazado del poder en 1956 por presión directa de Jrushov. Rákosi fue trasladado a territorio soviético a fin de impedir su asesinato, debido a los efectos de su sanguinaria política de exterminio conocida como "táctica de salami" o aniquilamiento del enemigo por tajadas (Aguirre,147) ${ }^{17}$

Durante la década de 1950, Hungría se sumió en un escabroso período dominado por Erinias, aquellas imperturbables diosas de la venganza. Su fugaz reemplazante fue Imre Nagy, quien había sido entronizado por obreros y estudiantes en octubre de 1956. Este no pudo hacer frente a los múltiples contubernios internos y se fugó a la vecina Rumania, pero fue rápidamente capturado y entregado a las nuevas autoridades del régimen húngaro, quienes procedieron a ahorcarlo tras fulminante juicio secreto en 1958 acusado de "traición a la patria socialista"

El nuevo líder, János Kádár, a la cabeza de una conspiración que reunía a comunistas filo-nacionalistas con otros pro-moscovitas, estabilizó el régimen adoptando un estilo marcado por oscilaciones entre tenues gestos de apertura, la pesadez gris característica de aquellos regímenes y la mantención de Budapest en la órbita geopolítica de Moscú. Gobernó el país hasta su muerte en 1989 y fue sucedido por un grupo de jóvenes dirigentes que de inmediato se trenzaron en una feroz disputa, protagonizada por sectores aperturistas de diversos matices que ocuparon por breves lapsos la jefatura del partido y del gabinete ministerial. El proceso derivó finalmente en una evidente descomposición institucional; o una desintegración psicológica y anómica, parafraseando a Huntington (44)

En medio del caos final, se dio la curiosa situación, que el verdadero acicate del desmantelamiento del régimen fue Imre Poszgay, un filósofo que sólo ejercía como ministro sin cartera desde 1988 y que fue miembro del parlamento hasta 1994. Bajo su inspiración, Hungría se desprendió de la órbita geopolítica soviética al proceder a la inédita apertura de la frontera con Austria garantizando asilo a miles de personas que huían de la RDA. Casi como efecto colateral, se llamó a elecciones generales y se inició el tránsito a la democracia.

En tanto, en Bulgaria, el régimen pro-soviético fue proclamado en 1947 de la mano de Georgi Dimitrov, quien murió en circunstancias no clarificadas dos años más tarde en un hospital de Moscú siendo reemplazado por Vasiliy Kolarov, cuyo mandato duró escasos meses al ser desplazado por su rival interno, Valko Chervenkov. Este gobernó con mano de hierro hasta 1956, cuando un complot liderado por Todor Zhivkov tomó el control del país e inició una tenue desestalinización.

\footnotetext{
${ }^{17}$ Rákosi fue uno de los más abyectos admiradores de Stalin en los regímenes comunistas. Su imitación llegó a extremos absurdos como hacerse llamar "maestro guía y hermano mayor de los obreros y campesinos húngaros", "héroe inmortal", "timón inmutable", "padre del acero", "padre del algodón", y otros. Logró sobreponerse a varios intentos de derrocamiento volviendo momentáneamente al poder. Al no poder controlar la sublevación en 1956, fue sacado del poder por las propias tropas soviéticas y llevado a Moscú.
} 
Sin embargo, al finalizar la década de los 80, el régimen de Zhivkov mostró signos de agotamiento y cayó en una profunda crisis de gobernabilidad que se acentuó con su fallecimiento. Ninguna de las facciones logró imponerse y Bulgaria se hundió en un grave vacío de poder. Esta circunstancia y las nuevas realidades de contexto que venían de una URSS dominada por Gorbachov, fue aprovechada por figuras disidentes para llamar a elecciones generales que pusieron fin al régimen comunista.

Por su parte, el comunismo se implantó en Rumania con Gheorge Gheorgiu-Dej, quien gobernó hasta su muerte en 1965. Tras disputas internas entre sus herederos, fue reemplazado por Nicolae Ceaușescu, cuyo tenebroso ejercicio del poder provocó un ambiente de odios que desencadenó su brutal ajusticiamiento el 25 de diciembre de 1989 , por parte de un grupo de militares que se disputó a viva fuerza un lugar en el pelotón de fusilamiento. Este hecho y su dramática huida previa, junto a su esposa, marcó uno de los hitos más dramáticos del fin del comunismo.

Por otro lado, el régimen comunista checoslovaco se inició en febrero de 1948 con Klement Gottwald y Rudolf Slánsky a la cabeza. Ambos venían protagonizando una de las disputas internas más violentas y sórdidas que registre la historia del comunismo mundial, debido a los fuertes disensos intra-partidarios y a las dificultades que tenía Moscú para controlar un partido inmerso en un régimen plenamente democrático. La democracia checoslovaca, pese al paréntesis nazi, hundía sus raíces con fuerza y vigor en la llamada primera república, instaurada en 1918, al derrumbarse el imperio austro-húngaro. Aquí también fueron invocadas las Erinias al acordar los comunistas checoslovacos su apoyo al Presidente Edvard Benes en orden a que el país se integrara al plan Marshall, asunto que colmó la paciencia de Moscú.

Stalin logró convencer a Gottwald en febrero de 1947 de la necesidad de desplazar a Slánsky y su grupo cosmopolita desatándose una cadena de venganzas que caracterizarían el resto de la historia del comunismo en aquel país. A poco andar, el cosmopolita Slánsky fue sentenciado a la horca junto a otros 13 miembros de su entorno más cercano (10 de los cuales eran judíos al igual que él). Gottwald se hizo con la conducción del partido y la Presidencia de la República. Sin embargo, en 1953, cinco días después de asistir al funeral de Stalin, falleció y fue reemplazado por Ladislav Zapotocky, quien murió cinco años más tarde por causas naturales desatándose al interior del partido otra feroz lucha intestina de la que resultó triunfador un gris apparatchick llamado, Antonín Novotny. Éste fue removido por una alianza de grupos liberalizadores en 1968, liderados por Alexander Dubcek, quien, a su vez, fue derrocado a los pocos meses por las tropas soviéticas. Moscú intentó poner fin al mare crisium de los comunistas checoslovacos instalando en el gobierno a otro apparatchik, Gustav Husák, en un proceso que se denominó "normalización" (Brown, p. 267-292) A los pocos años y con su salud debilitada, Husak se mostró incapaz de arbitrar las nuevas pugnas internas cayendo en 1987 sin que alguna de las facciones pudiera imponerse. De emergencia, asume el entonces ministro del Interior, Milos Jakes.

La vorágine de contubernios y deslealtades derrumbó a Jakes a mediados de 1989, siendo sucedido por Karel Urbánek, quien duró apenas dos meses en el poder. Asumió un auto-llamado renovador, Ladislav Adamec quien efectivamente se planteó abrir el régimen a la brevedad. Para ello, nombró, inéditamente, un Premier provisional para la parte checa y otro para la parte eslovaca del país, generando un inédito federalismo que desató una curiosa disputa acerca de la denominación real del país: República Checa- 
Eslovaca o República Checa y Eslovaca. Simultáneamente, Adamec llamó a elecciones generales parlamentarias, las cuales pusieron fin por medios constitucionales al régimen comunista en 1989 iniciándose, a raíz de esta vía pacífica e inédita en relación a lo que ocurrió en los demás países comunistas, la llamada Revolución de Terciopelo. Los parlamentarios electos procedieron a designar Presidente de la República al dramaturgo Václav Havel, el más conocido disidente que tuvo el régimen, y a Alexander Dubcek ${ }^{18}$ como Presidente del parlamento. Ambos iniciaron una nueva etapa política pero no pudieron detener la voluntad de división entre checos y eslovacos -también pacífica y acordada hasta en sus más nimios detalles- y que fue conocida como Divorcio de Terciopelo.

Por su lado, el devenir comunista polaco tuvo sobresaltos enormes desde sus inicios, debido a la conmoción interna que provocó el asesinato de todo el Comité Central por parte de agentes soviéticos tras una orden de Stalin; hecho ocurrido en el bienio $1938-1939^{19}$. Tras la proclamación del comunismo en 1947 , se desató una fuerte lucha interna entre los dos líderes del partido (Obrero Unificado de Polonia, según su denominación oficial), Wladyslaw Gomulka y Boleslaw Bierut. Triunfó éste último, aunque se vió obligado a mantener con vida (en prisión) a su rival, a fin de evitar una desestabilización mayor. Luego se dio el curioso hecho que Bierut asistió invitado a Moscú al discurso donde Jruschov anunció la desestalinización y sufrió durante la alocución un fulminante ataque cardíaco que le provocó la muerte sin alcanzar a regresar a Varsovia.

El vacío de poder renovó viejas rencillas en Varsovia y Gomulka, triunfador, salió de la prisión y asumió la conducción del régimen hasta 1970 cuando fue desplazado por un complot encabezado por Edward Gierek. Este, a su vez, fue víctima de un nuevo complot en la cúpula, diez años más tarde, siendo reemplazado por Stanislaw Kania, quien, sin embargo, no logró contener el fuerte descontento de la población polaca con el régimen. Abruptamente, éste se resquebraja y hunde en una crisis terminal. Kania, incapaz de contener las huelgas promovidas por el sindicato Solidarnosc, y abordar el clima adverso gestado por la Iglesia Católica que se encontraba en la cúspide de su popularidad gracias al papado de Karol Wojtytla, más conocido como Juan Pablo II, se ve obligado a llamar a los militares que desplazan a Kania.

El golpe militar, entendido como ultima ratio del comunismo polaco, ññeva al poder al general Wojciech Jaruzelski, quien aplica la ley marcial en 1981, pero no logra evitar el colapso. Este ocurre tras las elecciones generales en 1990, ganadas por el líder de Solidarnosc, Lech Walesa, con quien Polonia inicia el tránsito hacia la democracia y una economía de mercado.

\footnotetext{
${ }^{18}$ Antiguo líder comunista que intentó liberalizar el régimen bajo el concepto socialismo con rostro humano (popularizado por la prensa como Primavera de Praga). Tras la invasión soviética en agosto de 1968, Alexander Dubcek no fue condenado a muerte ni procesado sino obligado a un aislamiento total en un bosque de Eslovaquia. Tras la revolución de terciopelo fundó el Partido Socialdemócrata de Eslovaquia y falleció en 1992 en un accidente automovilístico.

${ }^{19}$ Stalin decidió incluso la disolución del Partido Comunista polaco acusándolo de "nacionalista" y "trotskista". En su discurso de 1956, en que Jrushov denuncia los crímenes de Stalin, éste pide formalmente perdón a los comunistas polacos sobrevivientes y anuncia la rehabilitación póstuma de sus dirigentes.
} 
Los ejemplos de los regímenes en Europa central y oriental tras la Segunda Guerra Mundial son indicativos de la imposibilidad estructural que demostraron en construir mecanismos de traspasos pactados en el poder.

Los casos planteados encuentran explicaciones que subyacen en los vestigios del estalinismo que, a través de la Tercera Internacional, intervino en la vida interna de prácticamente todos los partidos comunistas del mundo. También en una mezcla de secretismo al interior de las cúpulas comunistas, de vasos comunicantes rigurosamente jerarquizados y una conducta obsesiva con la disciplina partidaria. Todo ello inmerso en soterradas disputas hermenéuticas en torno a textos de Marx, Lenin o de algún otro gran ideólogo. Se trató entonces de un conjunto de factores que apagaron la vida al interior de los escasos espacios de acción política.

\section{Conclusiones}

La tragedia política de los regímenes comunistas radica en que la evidencia empírica demuestra a cabalidad su imposibilidad de generar mecanismos exitosos para canalizar las pulsiones internas. Razones van desde la no separación constitucional entre los asuntos del partido y aquellos del Estado, la inexistencia de instancias arbitradoras hasta una cotidianeidad política gris e infecunda, salpicada de purgas, traiciones y deslealtades, solían terminar con la muerte o la prisión.

La práctica política al interior de cada partido se circunscribió a cúpulas, cuyo ambiente estaba dominado por secretismos rigurosos, férrea disciplina y soterradas disputas sobre la ortodoxia marxista-leninista y sobre interpretaciones de tipo geopolítico en función de los intereses de Moscú.

Como resultado de estos factores, los regímenes de dictadura del proletariado fueron completamente incapaces de resolver todo tipo de crisis, desde luchas facciosas menores hasta grandes quiebres políticos que obligaron a algunas intervenciones militares soviéticas, como en los casos germanooriental en 1953, húngaro en 1956 y checoslovaco en 1968 o bien golpes militares domésticos como en Polonia en 1981. Esta limitante, al tener carácter estructural, desembocó inevitablemente en complots a la hora de pensar en relevos.

Pese a ello, hubo tres intentos por propiciar sucesiones pacíficas y ordenadas, de Roberto Robaina en Cuba, de Werner Lamberz en la RDA y la de Lin Biao en la RPCh. Las tres fracasaron por motivos distintos, pero son reveladoras de la cierta incomodidad que tenía la nomenklatura en su conjunto con los factores antes mencionados. Los tres son bastante ilustrativos por los matices que representan. Lin Biao fue designado de manera explícita, R. Robaina, implícita y W. Lamberz percibido como tal. Ninguno tuvo éxito.

\section{Bibliografía:}

Agence France Presse (1980, 19 noviembre) "Lin Biao, un personaje para la nueva China”, El País. Disponible en http://www.elpais.es . Consultado 08.03.2018.

Aguirre Pedro (2014) Historia mundial de la megalomanía, Debate, México, Arreola, Gerardo (2011, 23 de agosto). "Roberto Robaina ve en el lienzo y el color su rena- 
Mare crisium: complots y conspiraciones como mecanismo político para el relevo de cúpulas (...) (69-88)

cimiento", La Jornada. Disponible en http://www.jornada.unam.mx . Consultado 03.03.2018.

Broto, Antonio "La muerte del líder Lin Biao sigue envuelta en el misterio 45 años después" La Razón 13.12.2016. Disponible en http://www.la-razon.com Consultado 08.03.2018.

Brown, Arch The rise and fall of Communism, HarpersCollins, New York, 2009.

Cubaencuentro "Robertico Robaina expone sus obras en Buenos Aires, por primera vez, pero no viaja". Disponible en http://www.cubaencuentro.com . Consultado 09.03.2018.

Der Spiegel "Der war der geborene Führer", 22/1976. Disponible en http://www.spiegel.de . Consultado 03.03.2018.

Der Spiegel "Robaina: Lasst uns endlich in Ruhe", 22/1992. Disponible en http://www.spiegel.de . Consultado 03.03.2018.

Der Spiegel Generationenwechsel auf Kuba", 15/1993. Disponible en http://www.spiegel.de . Consultado 03.03.2018.

Dobrynin, Anatoly, En confianza, FCE, México, 1998.

Huntington, Samuel El orden político en las sociedades en cambio, Paidós, Madrid, 2006.

JoshuaProjectCountries: Lybia, Joshua project. Disponible en http://www.joshuaproject.net _. Consultado 02.03.2018.

Kissinger, Henry On China Random House Mondadori, Buenos Aires, 2012.

Lenin V.I. (2015) ¿Qué hacer?, Akal, Madrid,.

Marschall, Renate "Ich wollte das Ende der Legenden" Lausitzer Rundschau. Disponible en http://www.Ir-online.de . Consultado 05.04.2018.

Guerrero, Natalia "William Morgan, el "comandante yanqui" que murió fusilado en Cuba", BBC Mundo, 22.03.2015. Disponible en http://www.bbc.com . Consultado 03.03.2018.

Larraya, José Miguel "Aznar recibe a Robaina para desdramatizar las relaciones diplomáticas con Cuba”, El País, 07.04.1998. Disponible en http://www.elpais.es . Consultado 08.03.2018.

Pieper, Alfons "Eigene Genosse stürzten Honecker. DDR-Machtwechsel" NWZ Online, 19.10.2009. Disponible en http://www.nwzonline.de . Consultado 04.04.2018.

Ponte, Antonio J. “El secreto mejor guardado de Fidel Castro", Diario de Cuba 28.11.2014. Disponible en http://www.diariodecuba.com . Consultado 03.03.2018.

Pötzl, Norbert "Der Tod des SED-Kronprinzen" Der Spiegel. Disponible en http://www.spiegel.de . Consultado 03.03.2018.

Richter, Steffen "Chinas unruhiger Machtwechsel", Die Zeit 12.04.2012. Disponible en http://www.zeit.de. Consultado 05.02.2018.

Reyes, Gerardo "Podrían salir a luz nexos de narcos mexicanos con Roberto Robaina". El 
Nuevo Herald 10.05.2010. Disponible en http://www.elnuevoherald.com . Consultado 08.03.2018.

Snow, Edgar (1968) Red star over China, Grove Editors, New York.

Stelkens, Jochen "Machtwechsel in Ost-Berlin" Viertelsjahrhefte des Instituts für Zeitgeschichte München $\mathrm{N}^{\circ} 45$, Heft 45, 1997. Disponible en http://www.ifzmuenchen.de. Consultado 03.04.2018

The New York Times "Cuba change means more of the same, with control at the top", 10.04.2009.

Vicent, Mauricio "Fidel Castro destituye a Robaina en Exteriores, en un clima de vuelta a línea dura y ortodoxa" El País 25.09.1999. Disponible en http://www.elpais.es . Consultado 08.03.2018.

"Castro expulsa del partido a Roberto Robaina, exministro de Exteriores", El País 02.08.2002. Disponible en http://www.elpais.es . Consultado 08.03.2018.

Fidel Castro destituye a Robaina, en un clima de vuelta a la línea dura y ortodoxa", El País 29.05.1999. Disponible en http://www.elpais.es . Consultado 08.03.2018.

"Castro expulsa del partido a Roberto Robaina, exministro de Exteriores" El País, 02.08.2002. Disponible en http://www.elpais.es . Consultado 08.03.2018.

Weiss, Sandra (2018, 26 de febrero) "Die Leute kennen Kuba nur mit den Castros" SRF. Disponible en http://www.srf.ch . Consultado 03.04.2018.

Westdeutsche Rundfunk “6. März 1978 - Tod des DDR-Politikers Werner Lamberz". Disponible en http://www1.wdr.de . Consultado 03.04.2018.

Witker, Ivan (2007) “El caso Honecker, el interés nacional y la política exterior de Chile. Contornos y trasfondo de un problema 'interméstico'", Estudios Públicos, Centro de Estudios Públicos N 105, Santiago. 